\title{
Pre-hospital delay among patients with acute myocardial infarction in Saudi Arabia
}

\author{
A cross-sectional study
}

Ahmed F. ALAhmadi, MBBS, SBPM, Mohammed F. ALSaedi, MBBS, Abdullah E. Alahmadi, MBBS, Mohammad G. Alharbi, MBBS, Ibraheem H. Alharbi, MD, Sami A. Radman Al-Dubai, MPH, PhD.

\begin{abstract}
الأهداف : تقدير وقت تأخر وصول المرضى للمستشفى بين المرضى الذين الذين يعانون

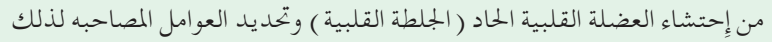
التأخر .

المنهجية : تم إجراء دراسة مقطعية بين 200 مريض يعانون من الجلطة القلبية في

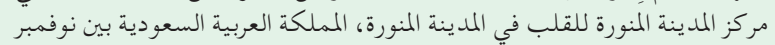

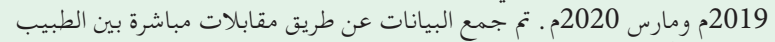

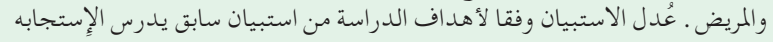

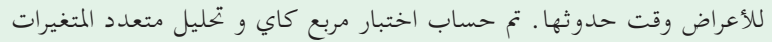

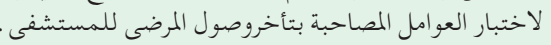

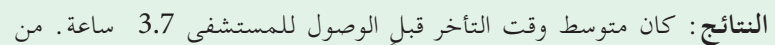

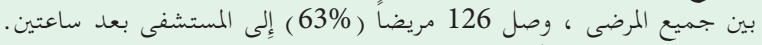

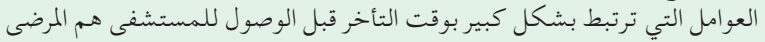

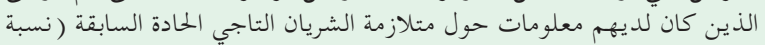

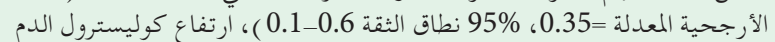

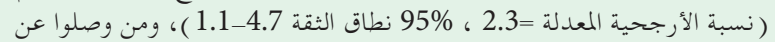
طريق سيارة الإِسعاف (نسبة الأرجحية المعدلة = 0.3 0. 0.8)، ومقياس الألم لديهم (نسبة الأرجحية المعدلة =0.7، 0. 0.

(0.6-0.9

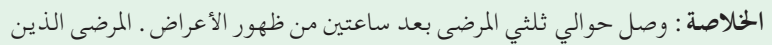

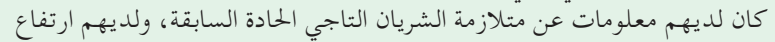

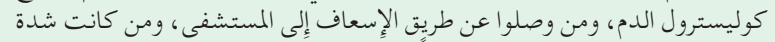

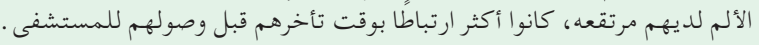

Objectives: To estimate the pre-hospital delay time among patients diagnosed with acute myocardial infarction and to determine factors associated with prehospital delay.

Methods: A cross-sectional study was conducted among 200 patients with myocardial infarction at Madinah Cardiac Center, Al Madinah Al Munawarah, Saudi Arabia between November 2019 and March 2020. Data were collected by direct physician-subject interviews. We used the validated version of the modified response to symptoms questionnaire. Chi-square test, $\mathrm{t}$ test, and multivariate analysis were used to examine factors associated with pre-hospital delay.

Results: The median pre-hospital delay time was 3.7 hours. Among all the patients, 126 patients (63\%) arrived at the hospital later than 2 hours from the onset of symptoms. Factors that were significantly associated with pre-hospital delay included a previous information on acute coronary syndrome (adjusted odds ratio [adj $\mathrm{OR}]=0.35$, 95\% confidence interval $[\mathrm{CI}]$ 0.1-0.6), history of hypercholesteremia (adj OR $=2.3,95 \%$ CI 1.1-4.7), arrived by ambulance (adj $\mathrm{OR}=0.3,95 \% \mathrm{CI}$ $0.1-0.8$ ), and increased pain intensity (adj OR=0.7, 95\% CI 0.6-0.9).

Conclusion: Approximately two-thirds of the patients arrived later than 2 hours from the onset of symptoms. A previous information about acute coronary syndrome, history of hypercholesteremia, arrived by ambulance, and increased pain intensity were associated with pre-hospital delay. The study recognizes the need for educational programs about acute myocardial infarction symptoms and the benefits of availing an ambulance service.

Keywords: myocardial infarction, ischemic heart diseases, pre-hospital delay, Saudi Arabia

Saudi Med J 2020; Vol. 41 (8): 819-827 doi: 10.15537/smj.2020.8.25185

From the Saudi Board of Preventive Medicine (ALAhmadi, Al-Dubai), from Primary Health Care Center (ALSaedi), from Madinah General Hospital (Alahmadi), and from Madinah Cardiac Center (Alharbi M, Alharbi I.), Ministry of Health, Al Madinah Al Munawarah, Kingdom of Saudi Arabia.

Received 15th May 2020. Accepted 24th June 2020.

Address correspondence and reprint request to: Dr. Ahmed F. ALAhmadi, Saudi Board of Preventive Medicine, Ministry of Health, Al Madinah Al Munawarah, Kingdom of Saudi Arabia.E-mail:afa.199199@gmail.com

ORCID ID: https://orcid.org/0000-0002-3275-243X 
$\mathrm{C}$ ardiovascular diseases (CVDs) are considered the number one cause of mortality worldwide. ${ }^{1}$ In 2016, CVD accounted for approximately $31 \%$ of all deaths globally and $37 \%$ of deaths in Saudi Arabia., 2,3

The recent improvement in the survival of patients with acute myocardial infarction (AMI) has been mostly attributed to early reperfusion therapy. ${ }^{4}$ Mortality reduction approaches $50 \%$ if intervention therapy is administered within the first 70 minutes. ${ }^{5}$ Pre-hospital delay is the "time between the onset of symptoms and arrival at an emergency department" in patients with AMI. ${ }^{6}$ In Saudi Arabia, 2 previous studies in 2013 had reported that the median delay time was 6 hours and in 2016 the median delay time was 3 hours. In the international studies, the median delay time was reported to range from 1.6 to 6.40 hours..$^{7-9}$

Many factors from different domains have been shown to influence pre-hospital delay include the misinterpretation of symptoms, which is attributed to poor or inappropriate knowledge, attitudes, and beliefs of AMI symptoms. ${ }^{10}$ In literature, factors associated with late arrival to hospital include female gender, old age, low socioeconomic status, history of chronic diseases, family history or previous history of angina, and failure to be transported by an ambulance. ${ }^{11} \mathrm{~A}$ few studies were conducted in Saudi Arabia with a varied range of pre-hospital delay times, and they showed that the majority of mortality was attributed to CVD. In Saudi Arabia, previous studies were inadequate and did not take in account common factors associated with pre-hospital delay. This study included other factors associated with pre-hospital delay such as knowledge, attitudes, and beliefs.

The aim of this study is to estimate the pre-hospital delay time among patients diagnosed with AMI and to determine the important factors influencing pre-hospital delay.

Methods. This study used a cross-sectional design. For all patients interviewed, file numbers were recorded to ensure that no duplications occurred within the sample set. The study was conducted between November 2019 and March 2020 at Madinah Cardiac Center (MCC), Al Madinah Al Munawarah, Saudi Arabia, a referral hospital for cardiac patients in Al Madinah City.

Disclosure. Authors have no conflict of interests, and the work was not supported or funded by any drug company.
The target population included all cases that were diagnosed by cardiologists as confirmed cases of AMI according to the most recent guidelines and admitted to the coronary care unit or medical ward within 24 and 72 hours of their admission at MCC during the study period. The study sample size was calculated using OpenEpi web based on the following assumption: the estimated prevalence of late arrival for patients who arrived to the hospital more than 2 hours was $80 \%$ (this prevalence was chosen based on previous study in the same region, and the statistical power was $80 \%$, with $95 \%$ confidence interval $[\mathrm{CI}]) .{ }^{12}$ Given this assumption, the minimum required number of cases was determined to be 183 patients. A convenient sampling technique was utilized to recruit 200 patients.

Patients were enrolled in the study if they: a) were over 18 years old, b) had a confirmed diagnosis of AMI indicated by either non-ST elevation myocardial infarction or ST-elevation myocardial infarction on electrocardiogram and laboratory results of troponin, creatine kinase- $\mathrm{MB}$, and creatine kinase according to the most recent guidelines, ${ }^{13}$ and c) could speak either English or Arabic. Patients were excluded if they: a) had impaired cognitive ability, b) were hemodynamically unstable, c) refused to participate, or d) were in the hospital for any reason when the AMI occurred.

The study instrument consisted of 4 parts. Part one included demographic variables such as gender, age, residential area, marital status, income, education, employment, and health insurance. Part 2 contained the date and time of symptoms onset and arrival at an emergency room. Pre-hospital delay time was defined as the time between the onset of symptoms and hospital arrival. ${ }^{6,89}$ Patients were classified into 2 groups based on the delay time. Early arrival was considered if the patients came to the hospital within 2 hours after the onset of symptoms. Late arrival was considered if the patients came more than 2 hours after symptoms onset. Two hours was used as a cut-off point because primary percutaneous coronary intervention loses its superiority over fibrinolysis beyond 2 hours following presentation. $^{14,15}$ Part 3 contained medical histories such as previous history of chronic diseases and cardiac surgeries that were retrieved from patient's files. It also included questions on patient's experiences of the occurrence of the first symptoms until hospital admission. ${ }^{16,17}$ Part 4 included the validated English and Arabic versions of the modified response to symptoms questionnaire that has 3 sections. ${ }^{18}$ The first section measured knowledge on coronary heart disease and AMI symptoms (26 items), with a total score ranging from 0 to 26 . Higher scores indicate high level of knowledge, 
and a score of 18 and above was considered good knowledge. The second section measured attitudes by using a 5-item questionnaire with a 4-point Likert-type scale. The answers for each item ranged from one (not at all) to 4 (very sure), and the total score ranged from 5 to 20. The coefficient alpha for the English version was 0.77 and the Arabic versions was 0.80, which was considered as a good internal consistency. The third section measured beliefs by using a 10 -item questionnaire. The answers range from one (strongly agree) to 4 (strongly disagree), and the total score ranged between 10 and 40. Higher scores indicated positive beliefs about AMI. The coefficient alphas for the English was 0.64 and the Arabic version was 0.70 , which is considered as a good internal consistency. ${ }^{17,19}$

The data collection was conducted between November 2019 and March 2020. Patients who participated in this study were interviewed using a structured questionnaire. The interview lasted for 15-20 minutes. Some information, such as date and time of arrival at the emergency room and history of chronic diseases, was taken from the medical records within 72 hours of their admission at MCC by trained data collectors. The study was approved ethically by the Institutional Review Board of the General Directorate of Health Affairs, Al Madinah Al Munawarah, Saudi Arabia according to the principles of the Declaration of Helsinki. Informed consent was obtained verbally from all participants. All patients were aware that their participation was voluntary, and their refusal to participate would not affect the quality of health care. All the data in the questionnaire were anonymous and stored in a secured location, only accessible by the research team.

Statistical analysis. Data were entered and subsequently managed using Statistical Package for Social Sciences, version 25 (IBM Corp, Armonk, NY, USA). Percentage and frequency were obtained for the categorical variables and mean \pm standard deviation (SD) or median (interquartile range [IQR]) for the continuous variables. Chi-square test was performed to assess the association between the categorical variables. Students' t-test was used to compare means across variables. Multiple logistic regression analysis was performed to determine the most important factors associated with pre-hospital delay. Sample size of 200 subjects was sufficient for logistic regression analysis according to the rule of thumb (10 subjects for each variable).

Multicollinearity test, Hosmer-Lemeshow goodness of fit test and the Nagelkerke R Square were obtained in the multiple logistic regression analysis. The accepted level of significance was below $0.05(p<0.05)$.

Results. Out of the 205 patients diagnosed with AMI, only 200 patients agreed to participate in the study (response rate=97.5\%). The median pre-hospital delay time was 3.7 hours (3.5 hours for males and 5.5 hours for females). Of the patients, $37 \%$ arrived at the hospital within 2 hours, and $63 \%$ arrived later than 2 hours. The mean age was $58.4(\mathrm{SD}=11.9)$ years, median age was $58(\mathrm{IQR}=50-67)$ and the ages ranged from 26 to 88 years.

The participants were predominantly Saudi (81\%), living inside $\mathrm{Al}$ Madinah $\mathrm{Al}$ Munawarah (68.5\%), male (83.5\%), married (97\%), and employed (40.5\%). Most of them had primary school education or below (40\%), income <4000 Saudi Riyal (42.5\%), and health insurance $(89.5 \%)$. Most of the patients also had a history of diabetes mellitus (57.5\%) and were never smokers (46\%). Approximately, $10.5 \%$ arrived at the hospital by ambulance (Table 1 ).

The mean pain scale score was $8.3(\mathrm{SD}=1.9)$. The mean knowledge of acute coronary syndrome score was $18.7(\mathrm{SD}=2.5)$. The mean attitudes score was 10.0 $(\mathrm{SD}=4.0)$, and the mean beliefs score was $24.2(\mathrm{SD}=2.0)$ (Table 2). A statistically significant association was found between smoking status and pre-hospital delay where current smokers were less likely to arrive late $(p=0.049)$. Patients who came to the hospital by ambulance were less likely to arrive late (odds ratio [OR] $=0.3,95 \% \mathrm{CI}$ 0.1-0.9, $p=0.043$ ). Other sociodemographic variables showed no significant association with pre-hospital delay (Table 3).

Patients who had received previous information on acute coronary syndrome were less likely to arrive late to the hospital (OR=0.4, 95\% CI 0.2-0.7, $p=0.003)$. Those who had a history of hypercholesteremia were more likely to arrive late to the hospital $(\mathrm{OR}=2.25$, 95\% CI 1.1-4.2, $p=0.012$ )(Table 4).

The mean pain scale was lower among those with delayed hospital arrival $(8.0 \pm 2.0)$ compared with those who arrived early $(8.8 \pm 1.5) \quad(p=0.004)$. The mean attitudes score was lower among those with delayed hospital arrival $(9.2 \pm 3.7)$ compared with those who arrived early $(11.3 \pm 4.2) \quad(p<0.001)$. The mean knowledge score was higher among those with delayed hospital arrival $(19.2 \pm 2.2)$ compared with those who arrived early $(18.0 \pm 2.9) \quad(p=0.001)$. No statistically significant differences were found in the beliefs score (Table 5).

Factors that were associated significantly with pre-hospital delay in bivariate analysis were entered 
Table 1 - Patient characteristics (N=200).

\begin{tabular}{|c|c|}
\hline Variable & n (\%) \\
\hline \multicolumn{2}{|l|}{ Age, years } \\
\hline$<50$ & $45(22.5)$ \\
\hline $50-65$ & $94(47.0)$ \\
\hline$>65$ & $61(30.5)$ \\
\hline \multicolumn{2}{|l|}{ Medical diagnosis } \\
\hline ST-segment elevation myocardial infarction & $110(55.0)$ \\
\hline $\begin{array}{l}\text { Non-ST-segment elevation myocardial } \\
\text { infarction }\end{array}$ & $90(45.0)$ \\
\hline \multicolumn{2}{|l|}{ Nationality } \\
\hline Saudi & $162(81.0)$ \\
\hline Non-Saudi & $38(19.0)$ \\
\hline \multicolumn{2}{|l|}{ Residential area } \\
\hline Inside $\mathrm{Al}$ Madinah $\mathrm{Al}$ Munawarah & $137(68.5)$ \\
\hline Outside Al Madinah Al Munawarah & $63(31.5)$ \\
\hline \multicolumn{2}{|l|}{ Gender } \\
\hline Male & $167(83.5)$ \\
\hline Female & $33(16.5)$ \\
\hline \multicolumn{2}{|l|}{ Marital status } \\
\hline Married & $194(97.0)$ \\
\hline Unmarried (single, widowed, divorced) & $6(3.0)$ \\
\hline \multicolumn{2}{|l|}{ Educational level } \\
\hline Primary school and below & $80(40.0)$ \\
\hline Intermediate or secondary school & $78(39.0)$ \\
\hline University or more & $42(21.0)$ \\
\hline \multicolumn{2}{|l|}{ Employment status } \\
\hline Employed & $81(40.5)$ \\
\hline Retired & $59(29.5)$ \\
\hline Unemployed & $60(30.0)$ \\
\hline \multicolumn{2}{|l|}{ Income (Saudi Riyals) } \\
\hline$<4000$ & $85(42.5)$ \\
\hline $4000-8000$ & $49(24.5)$ \\
\hline$>8000$ & $66(33.0)$ \\
\hline \multicolumn{2}{|l|}{ Insurance } \\
\hline Yes & $179(89.5)$ \\
\hline No & $21(10.5)$ \\
\hline \multicolumn{2}{|l|}{ Medical history } \\
\hline Coronary artery disease & $39(19.5)$ \\
\hline Previous acute coronary syndrome information & $78(39.0)$ \\
\hline Angina & $59(29.5)$ \\
\hline Myocardial infarction & $50(25.0)$ \\
\hline Cardiac surgery & $31(15.5)$ \\
\hline Hypercholesteremia & $71(35.5)$ \\
\hline Hypertension & $104(52.0)$ \\
\hline Diabetes & $115(57.5)$ \\
\hline Obesity & $54(27.0)$ \\
\hline Percutaneous coronary intervention & $19(9.5)$ \\
\hline Family history & $49(24.5)$ \\
\hline \multicolumn{2}{|l|}{ Smoking } \\
\hline Current & $64(32.0)$ \\
\hline Former & $44(22.0)$ \\
\hline Never & $92(46.0)$ \\
\hline \multicolumn{2}{|l|}{ Self-perceived cardiac symptoms } \\
\hline Yes & $94(47.0)$ \\
\hline No & $106(53.0)$ \\
\hline \multicolumn{2}{|l|}{ Previous experience of symptoms } \\
\hline Yes & $55(27.5)$ \\
\hline No & $145(72.5)$ \\
\hline \multicolumn{2}{|l|}{ Mode of hospital transport } \\
\hline Ambulance & $21(10.5)$ \\
\hline Other & $179(89.5)$ \\
\hline
\end{tabular}

Table 2 - Description of pain scale and cognitive variables in the study $(\mathrm{N}=200)$.

\begin{tabular}{lccc}
\hline Variable & Range & Mean (SD) & Median (IQR) \\
\hline Pain scale & $1-10$ & $8.3(1.9)$ & $8(7-10)$ \\
Knowledge & $8-24$ & $18.7(2.5)$ & $19(17-21)$ \\
Attitudes & $5-19$ & $10.0(4.0)$ & $10(6-13)$ \\
Beliefs & $17-30$ & $24.2(2.0)$ & $24(23-25)$ \\
\hline \multicolumn{4}{c}{ SD: standard deviation, IQR: interquartile range } \\
\hline
\end{tabular}

in the multiple logistic regression analysis (smoking, mode of hospital transport, previous ACS information, hypercholesteremia, self-perceived cardiac symptoms, pain scale, knowledge, and attitudes). Multiple logistic regression analysis showed that patients who had previous information on acute coronary syndrome $(\mathrm{OR}=0.35,95 \% \mathrm{CI} 0.1-0.6)$, those who came to the hospital by ambulance $(\mathrm{OR}=0.3,95 \% \mathrm{CI} 0.1-0.8)$, and those who had increased pain intensity $(\mathrm{OR}=0.7,95 \%$ CI 0.6-0.9) were less likely to arrive late to the hospital. Patients who had a history of hypercholesteremia $(\mathrm{OR}=2.3,95 \%$ CI 1.1-4.7, $p=0.019)$ were more likely to arrive late to the hospital (Table 6). The total model was significant $(p=0.003)$. Nagelkerke $\mathrm{R}$ square is 0.584 which shows that $58.4 \%$ of the variation in the pre-hospital delay is explained by this logistic model. Hosmer-Lemeshow goodness of fit test indicates that the model fits the data $(p=0.543)$.

There was no multicollinearity between the variables in the model as indicated by the correlation matrix analysis.

Discussion. The current study showed that $63 \%$ of the patients arrived later than 2 hours to the hospital. This percentage was considered higher than that reported in developed countries $(51.4 \%$ to $59 \%)$ and lower than that reported in developing countries (67.7\% to $81 \%) .{ }^{12,20-22}$ The median pre-hospital delay in this study was 3.7 hours. Studies conducted in Saudi Arabia in 2013 reported a median delay time of 6 hours and in 2016 a median delay time of 3 hours. ${ }^{7,8}$ In other countries, the median pre-hospital delay time was 2 hours in Turkey, 23 to 5 hours in Sweden, ${ }^{24,25}$ and 2.5 to 4 hours in China. ${ }^{26,27}$ The mean age of the participants in this study was similar to that in a study in Malaysia. ${ }^{28}$ Previous studies found that females were more likely to arrive late compared with males, but our findings failed to find statistically significant differences between males and females. ${ }^{16,29,30}$

In the current study, bivariate analysis showed that current smokers were less likely to arrive late, and current smokers might perceived high susceptibility to 
Table 3 - Sociodemographic characteristics associated with pre-hospital delay among patients with acute myocardial infarction $(\mathrm{N}=200)$.

\begin{tabular}{|c|c|c|c|c|}
\hline Variable & Late arrival $>2$ hours & Early arrival $\leq 2$ hours & OR $(95 \% \mathrm{CI})$ & $P$-value \\
\hline \multicolumn{5}{|l|}{ Age, years } \\
\hline$<50$ & $23(51.1)$ & $22(48.9)$ & & \multirow[t]{3}{*}{0.152} \\
\hline $50-65$ & $61(64.9)$ & $33(35.1)$ & & \\
\hline$>65$ & $42(68.9)$ & $19(31.1)$ & - & \\
\hline \multicolumn{5}{|l|}{ Medical diagnosis } \\
\hline $\begin{array}{l}\text { ST-segment elevation myocardial } \\
\text { infarction }\end{array}$ & $63(57.3)$ & $47(42.7)$ & $0.57(0.31-1.03)$ & \multirow[t]{2}{*}{0.064} \\
\hline $\begin{array}{l}\text { Non-ST-segment elevation myocardial } \\
\text { infarction }\end{array}$ & $63(70.0)$ & $27(30.0)$ & 1 & \\
\hline \multicolumn{5}{|l|}{ Nationality } \\
\hline Saudi & $102(63.0)$ & $60(37.0)$ & $0.99(0.47-2.06)$ & \multirow[t]{2}{*}{0.982} \\
\hline Non-Saudi & $24(63.2)$ & $14(36.8)$ & 1 & \\
\hline \multicolumn{5}{|l|}{ Residential area } \\
\hline Inside Al Madinah Al Munawarah & $86(62.8)$ & $51(37.2)$ & $0.97(0.52-1.80)$ & \multirow{2}{*}{0.922} \\
\hline Outside Al Madinah Al Munawarah & $40(63.5)$ & $36(36.5)$ & 1 & \\
\hline \multicolumn{5}{|l|}{ Gender } \\
\hline Male & $104(62.3)$ & $63(37.7)$ & $0.82(0.37-1.81)$ & \multirow[t]{2}{*}{0.633} \\
\hline Female & $22(66.7)$ & $11(33.3)$ & 1 & \\
\hline \multicolumn{5}{|l|}{ Marital status } \\
\hline Married & $123(63.4)$ & $71(36.6)$ & $1.73(0.34-8.81)$ & \multirow[t]{2}{*}{0.503} \\
\hline Unmarried & $3(50.0)$ & $3(50.0)$ & 1 & \\
\hline \multicolumn{5}{|l|}{ Educational level } \\
\hline Primary school and below & $53(66.3)$ & $27(33.8)$ & & \multirow[t]{3}{*}{0.066} \\
\hline Intermediate or secondary school & $53(67.9)$ & $25(32.1)$ & & \\
\hline University or more & $20(47.6)$ & $22(52.4)$ & - & \\
\hline \multicolumn{5}{|l|}{ Employment status } \\
\hline Employed & $48(59.3)$ & $33(40.7)$ & & \multirow[t]{3}{*}{0.065} \\
\hline Retired & $33(55.9)$ & $26(44.1)$ & & \\
\hline Unemployed & $45(75.0)$ & $15(25.0)$ & - & \\
\hline \multicolumn{5}{|l|}{ Income (Saudi Riyals) } \\
\hline$<4000$ & $56(65.9)$ & $29(34.1)$ & & \multirow[t]{3}{*}{0.536} \\
\hline $4000-8000$ & $32(65.3)$ & $17(34.7)$ & & \\
\hline$>8000$ & $38(57.6)$ & $28(42.4)$ & - & \\
\hline \multicolumn{5}{|l|}{ Insurance } \\
\hline Yes & $114(63.7)$ & $65(36.3)$ & $1.31(0.52-3.28)$ & \multirow[t]{2}{*}{0.557} \\
\hline No & $12(57.1)$ & $9(42.9)$ & 1 & \\
\hline \multicolumn{5}{|l|}{ Smoking } \\
\hline Current & $19(29.7)$ & $45(70.3)$ & $0.49(0.23-0.91)$ & 0.049 \\
\hline Former & $23(52.3)$ & $21(47.7)$ & $1.26(0.27-2.54)$ & \multirow{2}{*}{0.064} \\
\hline Never & $32(34.8)$ & $60(65.2)$ & 1 & \\
\hline \multicolumn{5}{|l|}{ Mode of hospital transport } \\
\hline Ambulance & $9(42.9)$ & $12(57.1)$ & $0.39(0.15-0.99)$ & \multirow[t]{2}{*}{0.043} \\
\hline Other & $117(65.4)$ & $62(34.6)$ & 1 & \\
\hline
\end{tabular}

have heart disease compared to non smokers. However, multivariate analysis showed no relationship between smoking and pre-hospital delay. A previous study showed that current smokers were less likely to arrive late. $^{21}$

In this study, only $10 \%$ of patients arrived to the hospital by ambulance. Previous studies in Saudi Arabia found that $8 \%$ and $19 \%$ arrived to the hospital by ambulance. ${ }^{7,8}$ We found that patients who did not use an ambulance were more likely to arrive late to the hospital compared with those who arrived by ambulance. This finding reflected that the ambulance use is the fastest mode of hospital transport as usual. A similar finding was reported in previous studies. ${ }^{8}, 31$

This study failed to detect a significant association between pre-hospital delay and other sociodemographic 
Pre-hospital delay in acute MI patients ... ALAhmadi et al.

Table 4 - Clinical characteristics associated with pre-hospital delay among patients with acute myocardial infarction (N=200).

\begin{tabular}{|c|c|c|c|c|}
\hline Variable & Late arrival $>2$ hours & Early arrival $\leq 2$ hours & OR $(95 \% \mathrm{CI})$ & $P$-value \\
\hline \multicolumn{5}{|c|}{ Medical history } \\
\hline \multicolumn{5}{|c|}{ Coronary artery disease } \\
\hline Yes & $24(61.5)$ & $15(38.5)$ & $0.92(0.45-1.90)$ & 0.833 \\
\hline No & $102(63.4)$ & $59(36.6)$ & 1 & \\
\hline \multicolumn{5}{|c|}{ Previous ACS information } \\
\hline Yes & $39(50.0)$ & $39(50.0)$ & $0.40(0.22-0.72)$ & 0.003 \\
\hline No & $87(71.3)$ & $35(28.7)$ & 1 & \\
\hline \multicolumn{5}{|l|}{ Angina } \\
\hline Yes & $40(67.8)$ & $19(32.2)$ & $1.34(0.70-2.56)$ & 0.364 \\
\hline No & $86(61.0)$ & $55(39.0)$ & 1 & \\
\hline \multicolumn{5}{|c|}{ Myocardial infarction } \\
\hline Yes & $35(70.0)$ & $15(30.0)$ & $1.51(0.76-3.01)$ & 0.238 \\
\hline No & $91(60.7)$ & $59(39.3)$ & 1 & \\
\hline \multicolumn{5}{|c|}{ Cardiac surgery } \\
\hline Yes & $24(77.4)$ & $7(22.6)$ & $2.25(0.91-5.52)$ & 0.760 \\
\hline No & $102(60.4)$ & $67(39.6)$ & 1 & \\
\hline \multicolumn{5}{|c|}{ Hypercholesteremia } \\
\hline Yes & $53(74.6)$ & $18(25.4)$ & $2.25(1.19-4.27)$ & 0.012 \\
\hline No & $73(56.6)$ & $56(43.4)$ & 1 & \\
\hline \multicolumn{5}{|c|}{ Hypertension } \\
\hline Yes & $66(63.5)$ & $38(36.5)$ & $1.04(0.58-1.85)$ & 0.888 \\
\hline No & $60(62.5)$ & $36(37.5)$ & 1 & \\
\hline \multicolumn{5}{|l|}{ Diabetes } \\
\hline Yes & $74(64.3)$ & $41(35.7)$ & $1.14(0.64-2.04)$ & 0.646 \\
\hline No & $52(61.2)$ & $33(38.8)$ & 1 & \\
\hline \multicolumn{5}{|l|}{ Obesity } \\
\hline Yes & $30(55.6)$ & $24(44.4)$ & $0.65(0.34-1.23)$ & 0.185 \\
\hline No & $96(65.8)$ & $50(34.2)$ & 1 & \\
\hline \multicolumn{5}{|c|}{$\begin{array}{l}\text { Percutaneous coronary } \\
\text { intervention }\end{array}$} \\
\hline Yes & $13(68.4)$ & $6(31.6)$ & $1.30(0.47-3.59)$ & 0.608 \\
\hline No & $113(62.4)$ & $68(37.6)$ & 1 & \\
\hline \multicolumn{5}{|c|}{ Family history } \\
\hline Yes & $35(71.4)$ & $14(28.6)$ & $1.64(0.81-3.32)$ & 0.162 \\
\hline No & $91(60.3)$ & $60(39.7)$ & 1 & \\
\hline \multicolumn{5}{|c|}{$\begin{array}{l}\text { Self-perceived cardiac } \\
\text { symptoms }\end{array}$} \\
\hline Yes & $52(55.3)$ & $42(44.7)$ & $0.53(0.30-0.95)$ & 0.034 \\
\hline No & $74(69.8)$ & $32(30.2)$ & 1 & \\
\hline \multicolumn{5}{|c|}{$\begin{array}{l}\text { Previous experience of } \\
\text { symptoms }\end{array}$} \\
\hline Yes & $39(70.9)$ & $16(29.1)$ & $1.62(0.83-3.17)$ & 0.154 \\
\hline No & $87(60.0)$ & $58(40.0)$ & 1 & \\
\hline
\end{tabular}

Table 5 - Main variables of the study associated with pre-hospital delay among patients with acute myocardial infarction (N=200).

\begin{tabular}{|c|c|c|c|c|}
\hline Variable & $\begin{array}{c}\text { Late arrival }>2 \text { hours, } \\
\text { mean }(\mathrm{SD})\end{array}$ & $\begin{array}{c}\text { Early arrival } \leq 2 \text { hours, } \\
\text { mean (SD) }\end{array}$ & Mean difference $(95 \% \mathrm{CI})$ & $P$-value \\
\hline Pain scale & $8.0(2.0)$ & $8.8(1.5)$ & $-0.8(-1.3-(-0.2))$ & 0.004 \\
\hline Knowledge & $19.2(2.2)$ & $18.0(2.9)$ & $1.19(0.4-1.9)$ & 0.001 \\
\hline Attitudes & $9.2(3.7)$ & $11.3(4.2)$ & $-2.0(-3.2-(-0.0))$ & $<0.001$ \\
\hline Beliefs & $24.0(2.0)$ & $24.5(1.9)$ & $-0.55(-1.1-0.0)$ & 0.058 \\
\hline
\end{tabular}


Table 6 - Multiple logistic regression analysis of factors associated with pre-hospital delay $(n=200)$.

\begin{tabular}{|c|c|c|c|c|}
\hline Variables & $\beta$ & Wald & Adjusted OR $(95 \% \mathrm{CI})$ & $P$-value \\
\hline \multicolumn{5}{|c|}{ Previous ACS information } \\
\hline Yes & -1.0 & 9.6 & $0.35(0.1-0.6)$ & 0.002 \\
\hline No & & & 1 & \\
\hline \multicolumn{5}{|l|}{ Hypercholesteremia } \\
\hline Yes & 0.8 & 5.4 & $2.3(1.1-4.7)$ & 0.019 \\
\hline No & & & 1 & \\
\hline \multicolumn{5}{|c|}{ Mode of hospital transport } \\
\hline Ambulance & -1.2 & 4.9 & $0.3(0.1-0.8)$ & 0.026 \\
\hline Other & & & 1 & \\
\hline Pain scale & -0.2 & 8.8 & $0.7(0.6-0.9)$ & 0.003 \\
\hline
\end{tabular}

factors such as age, educational level, nationality, and residential area. A previous study in Saudi Arabia found that pre-hospital delay was associated with a low educational level and living outside the city. ${ }^{7}$

Our study found a significant association between pre-hospital delay and knowledge and attitudes in the bivariate analysis but not in multivariate analysis. Similar findings were reported by a study in Jordan; however, beliefs were also associated with pre-hospital delay. ${ }^{18}$ Another study found that inadequate knowledge was associated with late hospital arrival. ${ }^{32}$

With regard to medical history, this study found that a history of hypercholesteremia and previous information about acute coronary syndrome were significantly associated with pre-hospital delay. A previous study found a significant association between hypercholesteremia and pre-hospital delay. ${ }^{7}$ Other previous studies found that patients who had history of hypercholesteremia were less likely to arrive late to the hospital. ${ }^{28,33}$

Patients who perceived the symptoms as cardiac in origin were less likely to arrive late to a hospital. ${ }^{27,34,35} \mathrm{~A}$ similar finding was reported in the current study.

Previous studies found that patients who reported an increased pain intensity were less likely to arrive late to a hospital. ${ }^{31,34,36}$ Similarly, the current study found that patients who had higher pain scale scores were less likely to arrive late to the hospital. This might be due to that patients with severe pain perceived their condition more serious.

Study limitations. First, recall bias could not be eliminated. Thus, to reduce the risk of bias, patients were interviewed within 72 hours by trained data collectors. Second, the study was carried out in a one center rather than a multicenter and a non-probability sampling technique was used; there was an inability to produce a representative sample of all AMI patients in the country. Third, factors associated with pre-hospital delay reflected only patients who reached the hospital and were hemodynamically stable. Exclusion of patients who died before reaching the hospital or patients who were hemodynamically unstable could affect the generalizability of the findings. Fourth, emotional factors such as anxiety or feeling worried and embarrassed for troubling others and patient's location distance from hospital were not included.

In conclusion, approximately two-thirds of the patients arrived to the hospital later than 2 hours after the onset of symptoms. Patients who had previous information about acute coronary syndrome, had a history of hypercholesteremia, arrived by an ambulance, and had increased pain intensity were more likely associated with pre-hospital delay. The present study highlights the need for educational programs regarding alarming symptoms of AMI for the public and the benefit of using ambulance system services to reduce delay time. Further interventional and qualitative research, are warranted to explore more factors influencing pre-hospital delay and raising awareness to promote early hospital arrival.

Acknowledgment. The authors gratefully acknowledge the participants involved in the study as well as Dr. Hasan I. Sandogji and Ms. Aisha M. Al Harbi of Madinah Cardiac Center, Al Madinah Al Munawarah, Saudi Arabia for facilitating the data collection. Also, we would like to thank Editage (www.editage.com) for English language editing.

\section{References}

1. World Health Organization. Cardiovascular diseases (CVDs). [Updated 2017. Cited 2020 April 27]. Available from URL: https://www.who.int/news-room/fact-sheets/detail/ cardiovascular-diseases-(cvds) 
2. World Health Organization. About cardiovascular diseases. [Updated 2017. Cited 2020 April 27]. Available from URL: https://www.who.int/cardiovascular_diseases/about_cvd/en/

3. World Health Organization. Global Health Observatory (GHO) data. Saudi Arabia: country profiles. [Updated 2017. Cited 2020 April 27]. Available from URL: https://www.who. int/gho/countries/sau/country_profiles/en/

4. Goldberg RJ, Yarzebski J, Lessard D, Gore JM. Decade-long trends and factors associated with time to hospital presentation in patients with acute myocardial infarction: the Worcester Heart Attack study. Arch Intern Med 2000; 160: 3217-3223.

5. Khan MS, Jafary FH, Faruqui AM, Rasool SI, Hatcher J, Chaturvedi N, et al. High prevalence of lack of knowledge of symptoms of acute myocardial infarction inPakistan and its contribution to delayed presentationto the hospital. $B M C$ Public Health 2007; 7: 284.

6. Mussi FC, Gibaut MD, Damasceno CA, Mendes AS, Guimaraes AC, Santos CA. Sociodemographic and clinical factors associated with the decision time for seeking care in acute myocardial infarction. Rev Lat Am Nursing 2013; 21 : 1248-1257.

7. Albrahim M, Ahmed AM, Alwakeel A, Hijji F, Al-Mallah MH. Predictors of delayed pre-hospital presentation among patients with ST-segment elevation myocardial infarction. Qatar Med J 2016; 2016: 7.

8. Alshahrani H, McConkey R, Wilson J, Youssef M, Fitzsimons D. Female gender doubles pre-hospital delay times for patients experiencing ST segment elevation myocardial infarction in Saudi Arabia. Eur J Cardiovasc Nurs 2014; 13: 399-407.

9. Wechkunanukul K, Grantham H, Clark RA. Global review of delay time in seeking medical care for chest pain: an integrative literature review. Aust Crit Care 2017; 30: 13-20.

10. Riegel B, McKinley S, Moser DK, Meischke H, Doering L, Dracup K. Psychometric evaluation of the acute coronary syndrome (ACS) response index. Res Nurs Health 2007; 30: 584-594.

11. Vidotto G, Bertolotti G, Zotti A, Marchi S, Tavazzi L. Cognitive and emotional factors affecting avoidable decision-making delay in acute myocardial infarction male adults. Int J Med Sci 2013; 10: 1174-1180.

12. Tabriz AA, Sohrabi MR, Kiapour N, Yazdani S. Factors associated with delay in thrombolytic therapy in patients with ST-elevation myocardial infarction. J Tehran Heart Cent 2012; 7: 65-71.

13. Thygesen K, Alpert JS, Jaffe AS, Chaitman BR, Bax JJ, Morrow DA, et al. Fourth universal definition of myocardial infarction (2018). J Am Coll Cardiol 2018; 72: 2231-2264.

14. Steg PG, James SK, Atar D, Badano LP, Lundqvist CB, Borger $M A$, et al. ESC Guidelines for the management of acute myocardial infarction in patients presenting with ST-segment elevation: The Task Force on the management of ST-segment elevation acute myocardial infarction of the European Society of Cardiology (ESC). Eur Heart J 2012; 33: 2569-2619.

15. Youssef GS, Kassem HH, Ameen OA, Al Taaban HS, Rizk $\mathrm{HH}$. Pre-hospital and hospital delay in patients with non-ST elevation acute coronary syndromes in tertiary care. Egypt Heart J 2017; 69: 177-181.

16. Noureddine S, Adra M, Arevian M, Dumit NY, Puzantian H, Shehab D, et al. Delay in seeking health care for acute coronary syndromes in a Lebanese sample. J Transcult Nurs 2006; 17: 341-348.
17. Buckley T, McKinley S, Gallagher R, Dracup K, Moser DK, Aitken LM. The effect of education and counselling on knowledge, attitudes and beliefs about responses to acute myocardial infarction symptoms. Eur J Cardiovasc Nurs 2007; 6: 105-111.

18. Darawad MW, Alfasfos N, Saleh Z, Saleh AM, HamdanMansour A. Predictors of delay in seeking treatment by Jordanian patients with acute coronary syndrome. Int Emerg Nurs 2016; 26: 20-25.

19. Alfasfos N, Darawad MW, Nofal B, Samarkandi OA, Abdulqader B. Knowledge, attitudes, beliefs and perceived risk of acute coronary syndrome among Jordanian patients. Health 2016; 8: 1830-1844.

20. Atzema CL, Austin PC, Huynh T, Hassan A, Chiu M, Wang JT, et al. Effect of marriage on duration of chest pain associated with acute myocardial infarction before seeking care. CMAJ 2011; 183: 1482-1491.

21. Peng YG, Feng JJ, Guo LF, Li N, Liu WH, Li GJ, et al. Factors associated with prehospital delay in patients with ST-segment elevation acute myocardial infarction in China. Am J Emerg Med 2014; 32: 349-355.

22. Ghazawy ER, Seedhom AE, Mahfouz EM. Predictors of delay in seeking health care among myocardial infarction patients, Minia District, Egypt. Adv Prev Med 2015; 2015: 1-6

23. Koc S, Durna Z, Akin S. Interpretation of symptoms as a cause of delays in patients with acute myocardial infarction, Istanbul, Turkey. East Mediterr Health J 2017; 23: 287-294.

24. Ängerud KH, Thylén I, Lawesson SS, Eliasson M, Näslund U, Brulin C, et al. Symptoms and delay times during myocardial infarction in 694 patients with and without diabetes; an explorative cross-sectional study. BMC Cardiovasc Disord 2016; 16: 108 .

25. Nilsson G, Mooe T, Söderström L, Samuelsson E. Pre-hospital delay in patients with first time myocardial infarction: an observational study in a northern Swedish population. BMC Cardiovasc Disord 2016; 16: 93.

26. Zhang B, Zhang W, Huang R, Zhu H, Liu J, Jiang D, et al. Gender and age differences associated with prehospital delay in Chinese patients presenting with ST-elevation myocardial infarction. Eur J Cardiovasc Nurs 2016; 31: 142-150.

27. Guan W, Venkatesh AK, Bai X, Xuan S, Li J, Li X, et al. Time to hospital arrival among patients with acute myocardial infarction in China: a report from China PEACE prospective study. EHJ-QCCO 2019; 5: 63-71.

28. Lim SC, Rahman A, Yaacob NM. Pre-hospital factors influencing time of arrival at emergency departments for patients with acute ST-elevation myocardial infarction. MJMS 2019; 26: 87-98.

29. Mohan B, Bansal R, Dogra N, Sharma S, Chopra A, Varma $S$, et al. Factors influencing prehospital delay in patients presenting with ST-elevation myocardial infarction and the impact of prehospital electrocardiogram. Indian Heart J 2018; 70: S194-198.

30. Assiri AS. Gender differences in clinical presentation and management of patients with acute coronary syndrome in Southwest of Saudi Arabia. J Saudi Heart Assoc 2011; 23: 135-141.

31. Xie L, Huang SF, Hu YZ. Factors influencing pre-hospital patient delay in patients with acute myocardial infarction. Chin. Nurs Res 2015; 2: 75-79. 
32. Albarqouni L, Smenes K, Meinertz T, Schunkert H, Fang $\mathrm{X}$, Ronel J, et al. Patients' knowledge about symptoms and adequate behaviour during acute myocardial infarction and its impact on delay time: findings from the multicentre MEDEA Study. Patient Educ Couns 2016; 99: 1845-1851.

33. Jäger B, Farhan S, Rohla M, Christ G, Podczeck-Schweighofer A, Schreiber W, et al. Clinical predictors of patient related delay in the VIENNA ST-elevation myocardial infarction network and impact on long-term mortality. Eur Heart J Acute Cardiovasc Care 2017; 6: 254-261.
34. Lesneski L. Factors influencing treatment delay for patients with acute myocardial infarction. Appl Nurs Res 2010; 23: 185-190.

35. Momeni M, Salari A, Shafighnia S, Ghanbari A, Mirbolouk F. Factors influencing pre-hospital delay among patients with acute myocardial infarction in Iran. Chin Med J 2012; 125 : 3404-3409.

36. Venkatesan VC, Madhavi S, Kuzhanthaivel P. A study to explore the factors related to treatment seeking delay among adults diagnosed with acute myocardial infarction at $\mathrm{KMCH}$, Coimbatore. Indian Heart J 2018; 70: 793-801.

\section{Illustrations, Figures, Photographs}

All figures or photographs should be submitted in a high resolution (minimum 300 DPI) electronic version saved in jpeg or tiff format. Original hard copies of all figures may be requested when necessary. Photographs will be accepted at the discretion of the Editorial Board. All lettering, arrows, or other artwork must be done by an artist or draftsman. If arrows are used please ensure they appear in a different color to the background color, preferably black with a white border, or white with a black border. If arrows distinguish different items on the figure then different arrow styles should be used ie. long, short, wide, narrow. Written informed consent for publication must accompany any photograph in which the subject can be identified. Written copyright permission, from the publishers, must accompany any illustration that has been previously published. 